\title{
Exploring Achievement Emotions of Medical Students During Problem-Based Learning Tutorials
}

\author{
Salah Eldin Kassab', Nahla Hassan ${ }^{2}$, Rabab Abdel Raoof ${ }^{*}$, Shimaa Elaraby ${ }^{2}$ \\ Nourhan Fawzy ${ }^{2}$, Ahmed Radwan ${ }^{2}$
}

'Department of Physiology, College of Medicine, Qatar University, ${ }^{2}$ Department of Medical Education, Faculty of Medicine, Suez Canal University, Egypt

\begin{abstract}
Background: Emotions are important contributors in students' motivation, learning and achievement. However, there is no current evidence addressing the students' emotions during the Problem-Based Learning (PBL) tutorials sessions. Aim: this study was planned with the purpose of investigating the students' academic emotions during the PBL tutorials. Methods: Achievement Emotion Questionnaire (AEQ) was used to assess achievement emotions of the students during PBL sessions. Data were collected from first- and second-year medical students $(n=287)$ during PBL tutorials at the Faculty of Medicine, Suez Canal University. Results: The total means of the activating achievement emotions in the first year are higher than in the second year. There was a significant difference between the means of the two years' responses in pride, enjoyment and anxiety ( $\mathrm{p}$-value: $0.000,0.001,0.000$ ) respectively by paired $t$-test. The internal consistency of the items was also measured by Cronbach alpha (0.94). Conclusion: Positive activating emotions like enjoyment, pride and hope are associated with innovative interactive learning strategy like PBL. Still tasks and problems should be more challenging to increase negative activating emotions like anxiety.
\end{abstract}

Key words: Educational psychology. Self-regulated learning. Control value theory

\section{Introduction}

Emotion has been defined in many ways in different academic disciplines. One simple definition of emotion is as an acute, intense, and typically brief psychophysiological change that results from a response to a meaningful situation in an individual's environment ${ }^{(1)}$. In the education and psychology literatures, emotion is usually thought of as an affective state, as opposed to a trait ${ }^{(2)}$. In addition, Emotions are experienced from an individual's point of view, and most psychologists agree they involve a set of related psychological processes with affective, cognitive, physiological, motivational, and expressive components(3). Control-value theory is a comprehensive, integrative approach to understanding emotions in education developed by Pekrun(4,5). Control-value theory groups achievement emotions by their valence (positive vs. negative, or pleasant vs. unpleasant); degree of activation (activating vs. deactivating); 
and object focus, as described above (activity vs. outcome)(6). Different emotions like enjoyment, boredom, and frustration certainly affect the students' preparation, motivation to persist in the face of difficulties, and the motivational strategies they employs to stay on task ${ }^{(1)}$. Artino et al., 2010 stated that medical students' motivational beliefs and achievement emotions are important contributors to their academic achievement. These results have implications for medical educators striving to understand the personal factors that influence learning and performance in medical training ${ }^{(1)}$ The relationship between emotions and learning is more complex. Although there are relatively consistent data indicating that heightened negative emotions, such as anxiety, typically hinder learning, and do so by generating an extraneous cognitive load $(7)$. Other previous studies have indicated that positive emotions can improve learning by enhancing motivation and problem solving ${ }^{(8,9)}$. In addition, findings in education and psychology suggest that emotions influence both cognition and motivation, which, in turn, affect learning and performance. In terms of cognition, the effects of emotion appear to be widespread and varied. There is no current evidence addressing the students' emotions during the PBL tutorials sessions, weather positive or negative. Therefore, this study was planned with the purpose of investigating the students' academic emotions weather positive or negative during the PBL tutorials.

\section{Subjects and Methods}

\section{Subjects}

Our participants were all the students in year $1(n=150)$ and all the students in year $2(n=137)$ at the Faculty of Medicine, Suez Canal University. the adopted school strategies are PBL (Problem Based Learning), student-centered, and Community-Based Education. The PBL tutorials are divided into two sessions, brain storming and debriefing session. Each session is a $1 \frac{1}{2}$ hours long. This study took place during one of the brains storming sessions of PBL tutorials.

\section{Methods}

To assess achievement emotions of the students, during PBL tutorial session, we used Achievement Emotion questionnaire $(A E Q)^{(3)}$. There are three sections in AEQ, containing the class-related, learningrelated, and test-related emotion scales. Within each section, the items are ordered in three blocks assessing emotional experiences before, during, and after being in achievement situations addressed by the section. In the class-related emotion scales, we used 43 items under the subscale of "during class". The items measure the following eight emotions: class-related enjoyment (4 items), hope ( 1 item), pride ( 5 items), anger ( 5 items), anxiety (5 items), shame (8 items), hopelessness ( 3 items), and boredom (10 items). The first three groups of emotions are positive, and the second five are negative. The questionnaire was translated into Arabic version for easier interpretation. The participants rated their feelings on a Likert Scale ranged from "strongly agree $=5$ " to "strongly disagree $=1$ ".

\section{Statistical Analysis}

This study is quantitative explorative study. The collected data were analyzed using SPSS 20.0, IBM. We used descriptive analysis (mean \pm standard dev-iation, SD) to display the subjective ratings of the eight emotions by the students during one of the PBL tutorial sessions. T-tests were conducted to investigate whether 
first and second year students' scale scores differed significantly $(p<0.01)$.

\section{Results}

Students in first year $(n=112)$, and students in second year $(n=131)$ responded to the questionnaire. The response rate from the first-year students was $75 \%$, while the response rate for second year students was $96 \%$.

Emotions in first year: The highest rated positive emotion is enjoyment (mean=3.7) while emotions of hope are the lowest (mean=3). Regarding negative emotions, the anger is the highest (mean=2.7) while shame and hopeless are the lowest (mean=2.4).

Emotions in second year: The highest rated positive emotion is pride (mean=3.1) while emotions of hope are the lowest (mean=2.9). Regarding negative emotions, the anger and boredom are the highest (mean of the both=2.5) while shame and anxiety are the lowest (mean=2.2).

Differences in emotions of first and second years: The total means of the activating achievement emotions in the first year are higher than in the second year. There was a significant difference between the means of the responses in pride, enjoyment and anxiety ( $p$-value: 0.001, $0.000,0.000$ respectively by paired t-test). The means of each emotion category in the two years are shown in table 1.

The reliability of the questionnaire: The internal consistency of the items was measured by Cronbach alpha (0.94). It indicates the high reliability of this tool in PBL context.

Table 1: Emotions of the medical students in the first and second years in PBL classes

\begin{tabular}{|l|c|c|c|}
\hline Emotion category & Year 1 & Year 2 & Sig. (2-tailed) \\
\hline - Pride & 3.6 & 3.1 & 0.001 \\
\hline - Hope & 3.0 & 2.9 & 0.298 \\
\hline - Enjoyment & 3.7 & 3.0 & 0.000 \\
\hline - Anxiety & 2.7 & 2.2 & 0.000 \\
\hline - Boredom & 2.5 & 2.5 & 0.927 \\
\hline - Shame & 2.4 & 2.2 & 0.107 \\
\hline - Anger & 2.7 & 2.5 & 0.648 \\
\hline
\end{tabular}

\section{Discussion}

Based on our results, pride, hope and enjoyment were the most perceived emotions among students during PBL tutorials. However, anxiety was not reported a high perceived emotion, it was significantly decreased in the second year. In a study by ${ }^{(10)}$ anxiety was reported as the most perceived negative emotion among students during the learning process. Many other studies that assessed achievement emotions reported the same result $^{(11,12)}$. Pekrun et al, 2002 in the same study found that positive emotions reported most often were enjoyment of learning, hope, pride, and relief. Moreover Tempelaar et al 2012 stated that positive emotions (especially enjoyment) contribute positively to achievement ${ }^{(10,13)}$. Emotions in PBL context have not been measured but old researches showing that PBL is an enjoyable experience for the students ${ }^{(14)}$ which is consistent with our results. In the current study we found a statistically significant difference between the first-year students and the second-year students regarding pride and enjoyment in favor of the first-year students. Eruglo et al 2006 explained this 
statistically significant difference between the first-year students and other years since first year students have still been at the beginning of their academic life, they are more optimistic ${ }^{(12)}$. This study also indicated a statistically significant difference between first year students and second year students regarding anxiety in favor of first year students. Some studies showed that participants reported frequent anxiety in learning situations that involved interacting with students and staff $(15,16)$. Similarly, in PBL tutorials where students are encouraged to interact with other colleagues and staff. Regarding the effect of the study year on the anxiety level, as we mentioned before this study showed that anxiety decreases with the level of study year, this finding was contradicted by another study which revealed that anxiety increases with the class level(17). Topham, Graham 2012 clarified that the increased anxiety with the class level in undergraduate programs is due to the fact that academic material becomes progressively more challenging, and anxieties rise where assessment includes performance or presentation ${ }^{(18)}$. Anxiety is considered one of the negative emotions, but it is still under the category of activating emotions ${ }^{(2)}$. In this study the cause of decreasing anxiety with class level may be due to the nature of learning tasks or due to the effect of learning method, thus students need some challenge in their academic tasks to be actively involved in their learning. An interesting result of Rusmono, 2013, in his study examining the relation between learning method, anxiety and mathematics achievement, showed that students with high anxiety level in PBL class perform better than those of high anxiety level in traditional class, while students with low anxiety level in PBL class perform lower than those with low anxiety level in traditional class. This emphasizes that learning tasks need to be challenging in PBL Tutorials to enhance student performance ${ }^{(19)}$. In another study by Akbiyik, 2012 that compared students' performance in demonstration session and tutorials in photo editing instruction, the demonstration group has low anxiety level and high performance in comparison to tutorial group who had high anxiety level and low performance, this may be due to the difference in the learning task ${ }^{(20)}$. Furthermore the impact of anxiety level on academic performance is not clear ${ }^{(21,22)}$. The item-total correlation of the scale was calculated using the Cronbach alpha coefficient. Cronbach coefficients were 0.94 for internal consistency. These results show that the internal consistency of the scale is high which means that the students' achievement emotions are significantly related. The same findings were found in other studies( 3,17$)$.

\section{Limitations}

This study has some limitations as we measured students' achievement emotions during class only. There is a need to measure emotions in other academic settings in medical school. Also, measuring emotions in one learning session is against the dynamic nature of emotions, thus more longitudinal studies that measure emotions across time are needed. The effect of negative and positive emotion on performance during PBL tutorials were not clear. The relation between emotions, motivation and cognitive variables were not revealed.

\section{Conclusion}

Positive activating emotions like enjoyment, pride and hope are associated with innovative interactive learning strategy like PBL. Still tasks and problems 
should be more challenging to increase negative activating emotions like anxiety.

\section{Acknowledgements}

We are thankful for participants for their cooperation. We are also grateful to Professor Reinhard Pekrun for his permission regarding the used tool.

\section{Conflicts of interests}

The authors declare that they have no conflicts of interests.

\section{References}

1. Artino AR, La Rochelle JS, \& Durning SJ. Second-year medical students' motivational beliefs, emotions, and achievement. 2010 Dec;44(12):1203-12. Medical Education

2. Artino A.R, Jr.,1, Eric S. Holmboez \& Steven J. Durning. (2012). Control-value theory: Using achievement emotions to improve understanding of motivation, learning, and performance in medical education: AMEE Guide No. 64

3. Pekrun R, Stephens EJ. 2010. Achievement emotions: A control-value approach. Soc Personal Psychol Compass 4:238-255.

4. Pekrun R. 2000. A social cognitive, control-value theory of achievement emotions. In: Heckhausen J, editor. Motivational psychology of human development. Oxford, England: Elsevier. pp 143163.

5. Pekrun R. 2006. The control-value theory of achievement emotions: Assumptions, corollaries, and implications for educational research and practice. Educ Psychol Rev 18:315-341.

6. Pekrun R, Frenzel AC, Goetz T, Perry RP. 2007. The control-value theory of achievement emotions: An integrative approach to emotions in education. In: Schutz PA, Pekrun R, editors. Emotion in education.

7. Kristin Fraser, Irene Ma, Elise Teteris, Heather Baxter, Bruce Wright \& Kevin McLaughlin Emotion, cognitive load and learning outcomes during simulation training 2012. MEDICAL EDUCATION 2012; 46: 1055-1062

8. Isen AM, Daubman KA, Nowicki GP. Positive affect facilitates creative problem solving. J Pers Soc Psychol 1987; 52:112231. 16

9. Isen AM, Reeve J. The influence of positive affect on intrinsic and extrinsic motivation: facilitating enjoyment of play, responsible work behavior, and selfcontrol. Motiv Emot 2005; 29:297-325.

10. Pekrun R, Goetz T, and Titz W. (2002). Academic Emotions in Students' SelfRegulated Learning and Achievement: A Program of Qualitative and Quantitative Research, EDUCATIONAL PSYCHOLOGIST,37(2), 91-105 Copyright @ 2002, Lawrence Erlbaum Associates, Inc

11. Lazarus, R. S. (1999). Stressd and emotions: A new synthesis. New York: Springer. Burlington, MA: Academic Press. pp 13-36.

12. Eroğlu S. E, Işiklar A, Bozgeyikli H, Research OF University Students' Academic Emotions Regarding Some Variables: Selçuk University Faculty OF Education Sample: Education Science and Psychology 2006 | No.2(9)

13. Tempelaar D.T, Niculescu A, Rienties B, Gijselaers W.H, Giesbers B. How achievement emotions impact students' decisions for online learning, and what precedes those emotions, Internet and Higher Education 15 (2012) 161-169.

14. Albanese MA, \& Mitchell S. (1993). Problem-based learning: A review of literature on its outcomes and implementation issues. Academic Med. 68, 52-81.

15. Scherer, KR. (2000). Emotions as episodes of subsystem synchronization driven by nonlinear appraisal process. In MD. Lewis \& I. Granic (Eds.), Emotion, development and self-organization: Dynamic systems approaches to emotional development (pp. 70-99). New York: Cambridge University Press.

16. Topham, P.W. (2009). 'Feeling stupid: A survey of university students' experience of social anxiety in learning situations'.UWERepository.https://eprints.uw 
e.ac.uk/164/.

17. YamacA. (2014). Classroom Emotions Scale for Elementary School Students (Ces-Ess), Mevlana International Journal of Education (MIJE) Vol. 4(1), pp. 150163, 1 April, 2014

18. Topham, P. and Russell, G. (2012) Social anxiety in higher education. The Psychologist, 25 (4). pp. 280-282. ISSN 09528229

19. Rusmono Ir. (2013). Effect of Learning Strategies and Anxiety of Learning Mathematics, the annual proceedings, Anaheim, volume 1 .

20. Akbiyik, C. (2012). A comparison of demonstration and tutorials in Photo Editing instruction, Educational Technology \& society, 15(3), 298-309.

21. Strahan, E.Y. (1998). The effects of social anxiety and social competence on undergraduate retention and academic performance. Dissertation. ETD Collection, Purdue University, Indiana. http://docs. lib.purdue.edu/cgi/query.cgi

22. Strahan, E.Y. (2003). The effects of social anxiety and social skills on academic performance. Personality and Individual Differences, 34 (2), 347-366. 